\title{
Kin selection or resource partitioning for growing with siblings: implications from measurements of nitrogen uptake
}

\author{
Li Zhang • Qianyuan Liu • Yuqiang Tian • \\ Xingliang Xu • Hua Ouyang
}

Received: 29 April 2015 / Accepted: 14 August 2015 / Published online: 22 August 2015

(C) Springer International Publishing Switzerland 2015

\begin{abstract}
Aims Kin selection and resource partitioning have been proposed to explain interactions between plants growing with siblings (from the same mother). These mechanisms have been examined by measurements of fitness, phenotype or allocation traits, but have seldom been tested with $\mathrm{N}$ acquisition traits.

Methods We determine if kin selection and resource partitioning are occurring using two annual species (Sorghum vulgare and Glycine max) with a short-term ${ }^{15} \mathrm{~N}$ experiment. A mixture of ammonium, nitrate and glycine (1:1:1) was injected into soils around plants after they grew for 47 days. Only one nitrogen $(\mathrm{N})$ form was ${ }^{15} \mathrm{~N}$ labeled in each labeling solution.

Results S. vulgare increased root allocation when growing with strangers (from the different mother), but not
\end{abstract}

Responsible Editor: Jeffrey Walck.

Qianyuan Liu contributed equally to this work.

L. Zhang $\cdot$ Q. Liu $\cdot$ X. Xu $(\bowtie) \cdot$ H. Ouyang

Key Laboratory of Ecosystem Network Observation and Modeling, Institute of Geographic Sciences and Natural Resources, Chinese Academy of Sciences, 11A, Datun Road, Chaoyang District, Beijing 100101, China

e-mail: xuxing1@hotmail.com

Y. Tian

State Key Laboratory of Earth Surface Processes and Resource Ecology, Beijing Normal University, No. 19, XinJieKouWai Street, Haidian District, Beijing 100875, China

L. Zhang • Q. Liu

University of Chinese Academy of Sciences, 19A, Yuquan Road, Shijingshan District, Beijing 100049, China increase their N uptake. Although G. max strangers did not increase their root allocation, they significantly increased uptake of total $\mathrm{N}$ and the most abundant $\mathrm{N}$ form (nitrate) and decreased uptake of the least abundant (glycine).

Conclusions G. max siblings reduced competition due to chemical resource partitioning while $S$. vulgare showed kin selection. We concluded that processes related to kin selection and resource partitioning can occur simultaneously, resulting in different competitive ability. These findings can improve our understanding of plants growing with siblings or strangers.

Keywords Sibling competition $\cdot$ Kin recognition $\cdot$ Kin selection $\cdot$ Resource partitioning . Competitive ability

\section{Introduction}

Plant competition strongly affects individual performance, population evolution and ecosystem structure and function. Plants compete for nutrients to meet their demands, and this competition occurs both within and between species (File et al. 2011). Many plant species are likely to grow close to siblings due to their limited dispersal distance and siblings are indeed experiencing competition (Masclaux et al. 2010). However, it remains unknown how these siblings growing together compete (Cheplick 1992) for available nutrients from soils. Clarifying this question will be beneficial for a better understanding of the consequence of its evolutionary and ecological significance (File et al. 2011; Simonsen et al. 2014). 
Numerous studies have suggested that plants have various foraging strategies to access patchy resources more efficiently, e.g., spreading their roots through different soil layers to maximize access to resources (Cahill et al. 2010) or associating with microbial symbionts to access different forms of nutrients (Reynolds et al. 2003; Bever et al. 2010; Simonsen et al. 2014). Such strategies have been observed for interspecific pairings which often reduce the competition through consuming different nitrogen $(\mathrm{N})$ forms (McKane et al. 2002; Xu et al. 2011). This is called "resource partitioning" (Cheplick and Kane 2004). Fierce competition should occur within species because they have more niche overlap between species (Murphy and Dudley 2009).

However, recent studies have shown that the competition between plants is more complicated than previously thought (Chu et al. 2008; Milla et al. 2009). Dudley and File (2007) demonstrate that Cakile edentula increases allocation to roots to increase competition when two individuals are strangers (from different mother plants of the same species), but not when they are siblings (from the same mother plants). Further studies about the competitive traits such as biomass allocation or fitness showed that kin recognition can occur in many plant species and facilitate growth of nearby siblings (Murphy and Dudley 2009; Biedrzycki and Bais 2010; Biedrzycki et al. 2010; Masclaux et al. 2010; Bhatt et al. 2011; Simonsen et al. 2014). Such kin recognition is assessed by the theory of kin selection based on Hamiltons' rule: $\mathrm{r}^{*} \mathrm{~b}>\mathrm{c} ; \mathrm{r}$ is the relatedness of the individuals, $\mathrm{b}$ is the benefit, and $\mathrm{c}$ is the cost of the altruistic trait expression (Hamilton 1964).

Initially, many studies have measured effects of growing with siblings or strangers on fitness (Cheplick and Kane 2004; Milla et al. 2009) to understand mechanisms of kin selection and resource partitioning. Subsequently, some studies have investigated effects of growth with siblings or strangers on morphological and allocation traits (Dudley and File 2007; Murphy and Dudley 2009; Biedrzycki et al. 2010). For example, plants growing with strangers increase allocation to roots to increase competition (Dudley and File 2007). When Arabidopsis thaliana growing with strangers, they produce more lateral roots and thus change root structure (Biedrzycki et al. 2010). Further study showed that root exudates mediate kin recognition through unknown signals (Biedrzycki et al. 2010). Recently, competitive ability was used to explain the siblings growing together (Masclaux et al. 2010; File et al. 2011).
However, no one has examined effects on $\mathrm{N}$ acquisition traits of growth with siblings or strangers. Such investigations will improve our understanding of plant interactions in plant communities.

Most previous studies determined the consequences of the fitness to identify kin selection and resource partitioning as potential driving forces for plants growing with siblings (File et al. 2011). In this study, we consider a new index in a resource context to evaluate the competition derived from root interactions. Of various nutrients, $\mathrm{N}$ is a major limiting one for plant growth in most terrestrial ecosystems (Vitousek and Howarth 1991; LeBauer and Treseder 2008). The amounts and forms of available soil $\mathrm{N}$ depend on the balance of $\mathrm{N}$ loss and $\mathrm{N}$ retention, which strongly influence the competition between plants. Under N-limited conditions, plants have to compete strongly for available $\mathrm{N}$ for survival. Numerous studies have suggested that $\mathrm{N}$ partitioning contributes to species coexistence in grasslands (McKane et al. 2002; Xu et al. 2011; Gao et al. 2014). Therefore, $\mathrm{N}$ is an ideal nutrient used to examine root interactions when the same species plants grow together. According to the resource theory, the niches of relatives have more overlap in sibling groups than in stranger groups. As a result, stranger groups should outperform sibling groups. To test this, we grew two annual species Sorghum vulgare and Glycine max in pair-wise experiments under field condition with the presence of neighbors that are siblings or strangers. After growing for 47 days, we labeled these plants with ${ }^{15} \mathrm{~N}$ tracers to quantify their $\mathrm{N}$ uptake. We aimed to test the following hypotheses: If kin selection occurs, siblings will outperform stranger groups. Otherwise, if strangers and siblings prefer different $\mathrm{N}$ forms, it will support resource-partitioning hypothesis.

\section{Material and methods}

Site

This study was conducted at the State Key Laboratory of Earth Surface Processes and Resource Ecology, Beijing Normal University, located in northwestern Hebei province $\left(40^{\circ} \mathrm{N}, 115^{\circ} \mathrm{E}\right)$. Annual precipitation averaged $370 \mathrm{~mm}$ and the mean annual temperature was $9.6^{\circ} \mathrm{C}$. The average temperature and precipitation in August was about 24.4 and $107.5 \mathrm{~mm}$ respectively. Soil 
characteristics of the top $15 \mathrm{~cm}$ at this site are shown in Table 1.

Seeds

Seeds of G. max and S. vulgare were collected from a farm in Shandong Province. The cultivars used for G. max and S. vulgare were Ludou No. 2 and Luliang No. 1, respectively. Seeds for each species were collected from two individuals of the same cultivar, which grew in the same plot with a distance of about three meters. Seeds from the same individual shared the same mother, while those from different individuals were from different mothers.

Treatments

Treatments for G. $\max$ and $S$. vulgare were as follows: The groups were either siblings (from the same mother plant) or strangers (from different mother plants). Paired micro-plots were used to evaluate siblings grown together, but there were no barriers to root growth. Paired micro-plots for the sibling treatments received two seeds from the same mother. Paired micro-plots for the stranger treatments received two seeds from different mothers. All the seeds were planted on July 25, 2013, and they were then maintained by periodic weeding and watering. Some seedlings were removed by hand, leaving only a single seedling in a micro-plot. These paired micro-plots with $10 \mathrm{~cm}$ distance between two individuals were micro-units (Fig. 1). These micro-units were divided into four groups for three $\mathrm{N}$ forms and the control, with 5 and 8 replicates for $G$. $\max$ and $S$. vulgare, respectively.

Table 1 Properties in the top $15 \mathrm{~cm}$ soil at the study site ( $n=16$ to 18)

\begin{tabular}{lll}
\hline Property & Mean & Standard deviation \\
\hline $\mathrm{pH}$ & 8.80 & 0.14 \\
Soil organic C $\left(\mathrm{g} \mathrm{kg}^{-1}\right)$ & 6.82 & 1.16 \\
Total N $\left(\mathrm{g} \mathrm{kg}^{-1}\right)$ & 1.42 & 0.00 \\
$\mathrm{NH}_{4}{ }^{+}-\mathrm{N}\left(\mathrm{mg} \mathrm{kg}^{-1}\right)$ & 1.71 & 0.23 \\
$\mathrm{NO}_{3}{ }^{-}-\mathrm{N}\left(\mathrm{mg} \mathrm{kg}^{-1}\right)$ & 6.08 & 2.45 \\
$\mathrm{Glycine}^{-1}\left(\mathrm{mg} \mathrm{kg}^{-1}\right)$ & 0.55 & 0.08 \\
\hline
\end{tabular}

Labeling

After plants grew for 47 days, they were labeled with $\mathrm{K}^{15} \mathrm{NO}_{3}$ (99.19 atom $\%{ }^{15} \mathrm{~N}$ enrichment), $\left({ }^{15} \mathrm{NH}_{4}\right)_{2} \mathrm{SO}_{4}$ $\left(99.14\right.$ atom $\%{ }^{15} \mathrm{~N}$ enrichment) or glycine (99.04 atom $\%{ }^{15} \mathrm{~N}$ enrichment). All three tracer solutions include ammonium, nitrate and glycine $\left(0.0625 \mathrm{gL}^{-1}\right.$ for each $\mathrm{N}$ form), but only one form was ${ }^{15} \mathrm{~N}$ labeled. Eight $\mathrm{mL}$ of tracer solution was injected into $5 \mathrm{~cm}$ depth at points around plants and finally each micro-plot received $1.5 \mathrm{mg}$ total $\mathrm{N}$. To ensure the tracer equal distribution, four points with $5 \mathrm{~cm}$ from the plant stems were injected with $2 \mathrm{~mL}$ solution. The ${ }^{15} \mathrm{~N}$ solutions were added as uniformly as possible horizontally and vertically.

\section{Sampling}

One hour after ${ }^{15} \mathrm{~N}$ injection, plants and soils were harvested from each micro-plot. Shoots and roots were washed carefully with distilled water and then dried at $65^{\circ} \mathrm{C}$ for $48 \mathrm{~h}$ for biomass. After then, they were ground with ball mill (MM2, Retsch, Haan, Germany) for measurements of $\mathrm{N}$ contents and ${ }^{15} \mathrm{~N} /{ }^{14} \mathrm{~N}$. Fresh soil samples were immediately brought to the laboratory and sieved to through $2 \mathrm{~mm}$ and stored at $4{ }^{\circ} \mathrm{C}$ for measurements of available $\mathrm{N}$ within 2 days.

\section{Analysis}

The $\mathrm{N}$ contents and ${ }^{15} \mathrm{~N} /{ }^{14} \mathrm{~N}$ for plant materials were determined on an isotope ratio mass spectrometry (MAT253, Finnigan MAT, Bremen, Germany) connected to an Elemental analyzer (EA 1112, CE Instruments, Milan, Italy). A pH analyzer was used to measure the supernatant with dry soil-water ratio of 1:2. Total soil $\mathrm{N}$ was measured by dry combustion (Vario Max; Elementar Analysensysteme GmbH, Hanau, Germany). Soil organic $\mathrm{C}$ was measured by the dichromate digestion method (Kalembasa and Jenkinson 1973). Fifteen grams of fresh soil was extracted with $60 \mathrm{~mL}$ $0.05 \mathrm{M} \mathrm{K}_{2} \mathrm{SO}_{4}$ for $1 \mathrm{~h}$ at $70 \mathrm{rev} / \mathrm{s}$ using a shaker. Soil $\mathrm{NH}_{4}{ }^{+}$and $\mathrm{NO}_{3}{ }^{-}$in extracts was measured on an auto analyzer (AA3, Bran-Luebbe, Germany). Soil glycine concentrations were measured by high-performance liquid chromatography (Waters 515, Waters Inc., USA) on the same extracts (Näsholm et al. 1987). 


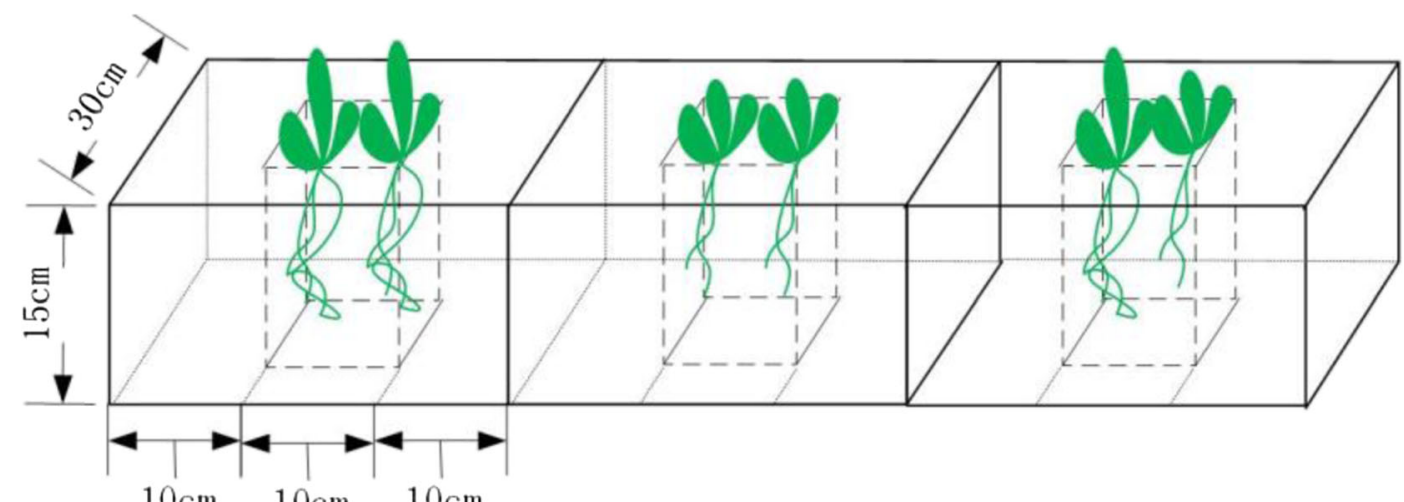

$10 \mathrm{~cm} \quad 10 \mathrm{~cm} \quad 10 \mathrm{~cm}$
Sibling -1
Sibling-2
Stranger

Fig. 1 Rectangle micro-units were used as an experiment design for Glycine max and Sorghum vulgare growing with a sibling or a stranger in the field. The different plant shapes represent different

Calculation and statistics

Amount of $\mathrm{N}$ uptake by plant was calculated multiplying N\% by atom percentage excess (APE) and total biomass. Nitrogen uptake rate was calculated dividing the amount of $\mathrm{N}$ uptake amount by time and root biomass. APE is the ${ }^{15} \mathrm{~N}$ difference between ${ }^{15} \mathrm{~N}$-treated and control plants. The plant $\mathrm{N}$ uptake $\left(\mathrm{U}_{\text {unlabeled }}\right)$ was estimated considering the native concentrations of corresponding $\mathrm{N}$ forms as follows: $\mathrm{U}_{\text {unlabeled }}=\mathrm{U}_{\text {labeled }}$ * $\left(\mathrm{m}_{\text {unlabeled }} / \mathrm{m}_{\text {labeled }}\right)$, where $\mathrm{U}_{\text {labeled }}$ is the quality of ${ }^{15} \mathrm{~N}$ per plant uptake from the soil, $\mathrm{m}_{\text {unlabeled }}$ is the native content of corresponding $\mathrm{N}$ form in control treatments, extracting with $0.05 \mathrm{M} \mathrm{K}_{2} \mathrm{SO}_{4}$, and $\mathrm{m}_{\text {labeled }}$ is the total mass of injected ${ }^{15} \mathrm{~N}$ to plants (McKane et al. 2002; Xu et al. 2011). The contribution of each $\mathrm{N}$ form was estimated as its percentage of total uptake for all three $\mathrm{N}$ forms.

Biomass was always normally distributed and thus not transformed. T-tests were used to compare behavior of plants competing with siblings or strangers on aboveground- and belowground- biomass. Three-way ANOVA was used to test the effect of species ( $G$. max and $S$. vulgare), kin (sibling and stranger), $\mathrm{N}$ forms (glycine, ammonium, and nitrate), and their interactions on plant $\mathrm{N}$ uptake. Also, t-tests were performed to compare the effect of sibling or stranger groups to plant total $\mathrm{N}$ uptake in a specific species. All statistic analysis was performed with SPSS 16 (SPSS Inc., Chicago, IL, USA) and considered significant at the $P<0.05$ level. siblings. Lines of these micro-units in the figure only indicate the distance between two plant individuals for different combinations, not the barriers for root growing

\section{Results}

\section{Biomass}

Whether grown with a sibling or a stranger, both $G$. $\max$ and $S$. vulgare did not show significant differences in aboveground biomass. Belowground biomass was not different between sibling and stranger groups for G. max, but $S$. vulgare growing with a sibling showed significantly lower belowground biomass than with a stranger (Fig. 2).

\section{Plant N uptake}

There was a significant effect of $\mathrm{N}$ form on plant $\mathrm{N}$ uptake, but there was no species effect. Among three $\mathrm{N}$ forms, $\mathrm{NO}_{3}{ }^{-}-\mathrm{N}$ was the dominant $\mathrm{N}$ resource, $\mathrm{NH}_{4}{ }^{+}-\mathrm{N}$ was the second and glycine- $\mathrm{N}$ was the least (Table 1). The effect of sibling on plant $\mathrm{N}$ uptake tended to be significant, with higher uptake for stranger groups than for siblings. Interactions between siblings and $\mathrm{N}$ form significantly affected plant $\mathrm{N}$ uptake. By comparison, the interactive effect of species, sibling, and $\mathrm{N}$ form showed a marginally significant effect on $\mathrm{N}$ uptake $(P=0.08$, Table 2). G. $\max$ and $S$. vulgare not only acquired $\mathrm{NH}_{4}{ }^{+}$and $\mathrm{NO}_{3}{ }^{-}$, but also took up organic $\mathrm{N}$ in the form of glycine. Both crops took up more $\mathrm{NO}_{3}{ }^{-}$ than glycine or $\mathrm{NH}_{4}{ }^{+}$, with higher $\mathrm{NH}_{4}{ }^{+}$than glycine uptake (Fig. 3).

$\mathrm{NH}_{4}^{+}$uptake was not significantly different between sibling and stranger groups for G. max and $S$. vulgare (Figs. 3 and 4). As to the uptake of glycine and $\mathrm{NO}_{3}{ }^{-}$, 


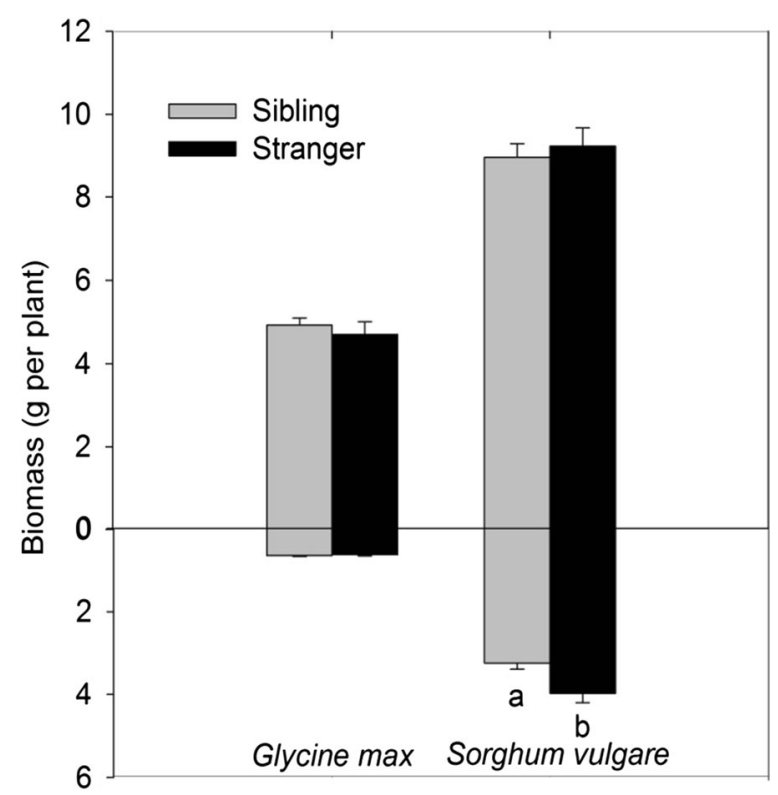

Fig. 2 Above- and below-ground biomass when Glycine max and Sorghum vulgare growing with a kin or a stranger. The values were mean $\pm \mathrm{SE}$ of five to eight replicates. Different letters under the bars indicate the significant difference between sibling and stranger treatments for either of species

sibling and stranger groups differed significantly for G. max. Siblings had higher uptake of glycine while stranger showed higher uptake of $\mathrm{NO}_{3}{ }^{-}$. Compared to sibling treatments, stranger increased total $\mathrm{N}$ uptake for G. max. However, such differences were not observed for S. vulgare (Figs. 3 and 4).

Among three $\mathrm{N}$ forms, $\mathrm{NO}_{3}{ }^{-}-\mathrm{N}$ made the greatest contribution to total N uptake for G. max and $S$. vulgare

Table 2 ANOVA results of the effects of species, siblings, $\mathrm{N}$ forms and their interactions on plant $\mathrm{N}$ uptake

\begin{tabular}{llll}
\hline Effect & df & F & Sig. \\
\hline Species & 1 & 1.488 & 0.23 \\
Kin & 1 & 2.74 & 0.10 \\
N form & 2 & 88.31 & $<\mathbf{0 . 0 0 1}$ \\
Species * Siblings & 1 & 2.28 & 0.13 \\
Species * N form & 2 & 1.20 & 0.30 \\
Siblings * N form & 2 & 3.47 & $\mathbf{0 . 0 3}$ \\
Species* Siblings * N form & 2 & 2.59 & 0.08 \\
Error & 127 & & \\
Total & 139 & & \\
Corrected Total & 138 & & \\
\hline
\end{tabular}

Number in bold indicates that the effect was significantly different at a $P<0.05$ level

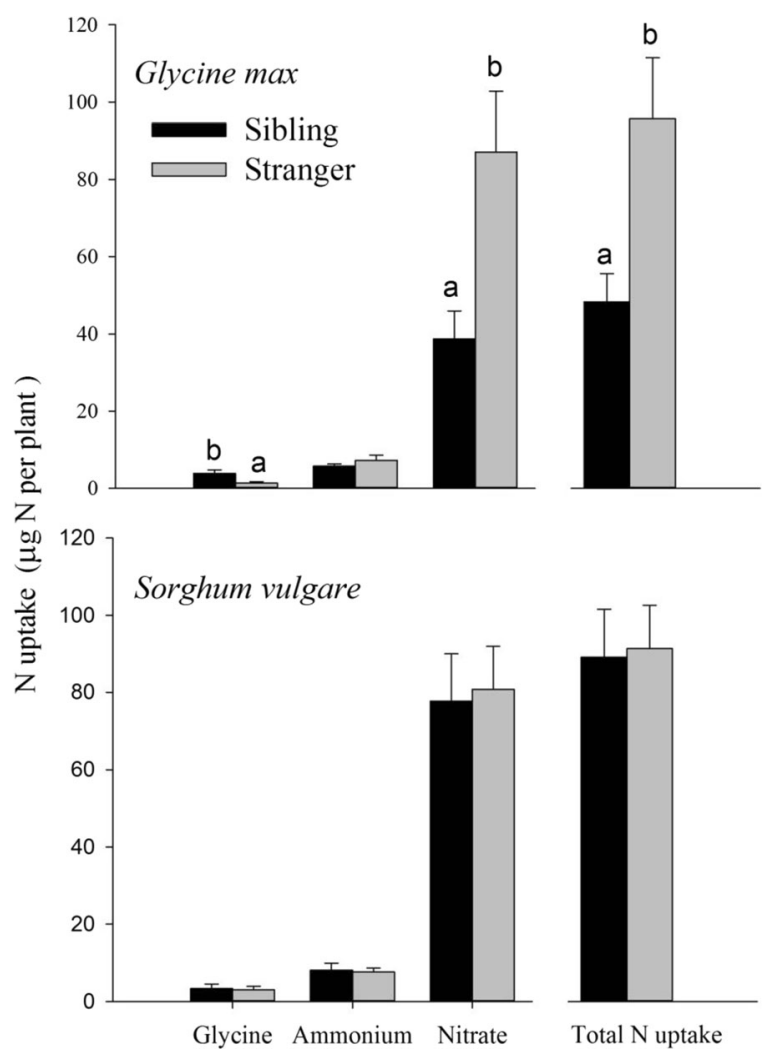

Fig. 3 Uptake of three $\mathrm{N}$ forms as well as total $\mathrm{N}$ uptake for Glycine max and Sorghum vulgare growing with a kin or a stranger. The values were mean $\pm \mathrm{SE}$ of five to eight replicates. Different letters above the bars indicate a significant difference between sibling and stranger treatments within an $\mathrm{N}$ form

(Fig. 5). Sibling and stranger groups for G. max showed significant niche shifts for glycine (Fig. 5).

\section{Discussion}

Kin selection and resource partitioning have been proposed to explain interactions between plants growing with siblings. These mechanisms have been extensively examined by measurements of biomass allocation and fitness. Here we tested biomass allocation and the competition for nutrients to improve our understanding of plant interactions in plant communities. We first demonstrated that G. $\max$ and $S$. vulgare have the capacity to take up organic $\mathrm{N}$ in form of glycine, but at very low rates compared to inorganic $\mathrm{N}$ (Fig. 3). A possible explanation is that glycine availability was too low in our soil. $\mathrm{NO}_{3}{ }^{-}$uptake contributes $80 \%$ to total $\mathrm{N}$ uptake. This clearly reflects that two agricultural species prefer $\mathrm{NO}_{3}{ }^{-}$over $\mathrm{NH}_{4}{ }^{+} /$glycine in the investigated soil. 


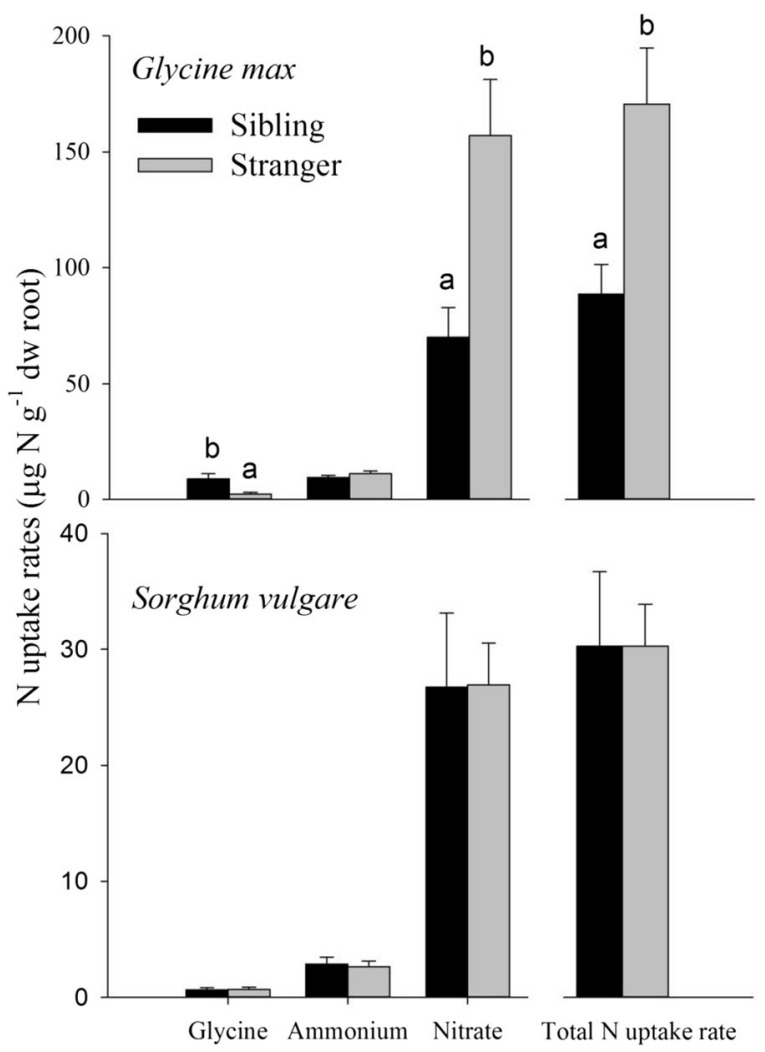

Fig. 4 Uptake rates (mean $\pm \mathrm{SE}$ ) of three $\mathrm{N}$ forms as well as of total N for Glycine max and Sorghum vulgare growing with a sibling or a stranger. Different letters above the bars indicate a significant difference between sibling and strange treatments for a single $\mathrm{N}$ form

This could be ascribed to high soil $\mathrm{pH}$ of 8.8 , because previous studies showed that plants prefer $\mathrm{NO}_{3}{ }^{-}$rather than $\mathrm{NH}_{4}{ }^{+}$in high $\mathrm{pH}$ soil. Another reason is that the investigated soil had high gas diffusion and could lead

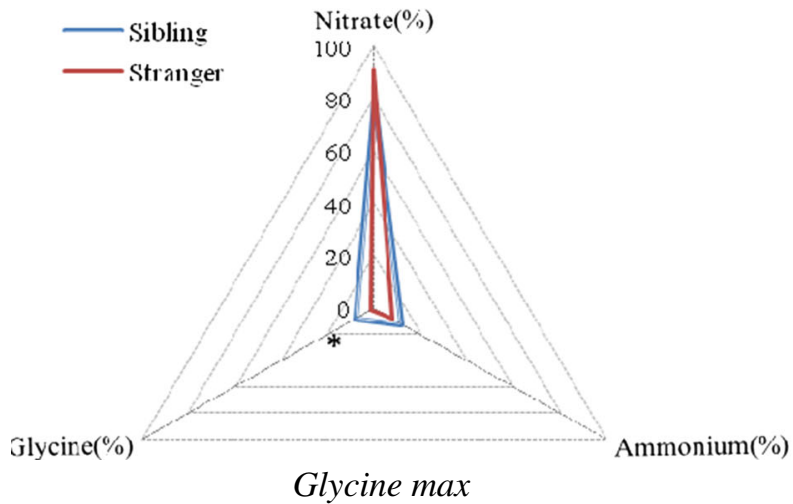

Fig. 5 Chemical niche shifts for Glycine max and Sorghum vulgare when growing with a kin or a stranger. The axes of $\mathrm{x}, \mathrm{y}$ and $\mathrm{z}$ represent the contribution of ammonium, nitrate and glycine to strong nitrification and thus produced more nitrate (Zhang et al. 2013). Under this condition, plants could prefer the dominant $\mathrm{N}$ form.

Furthermore, we examined the theories of kin selection and resource partitioning invoked for interactions between siblings growing together within a nutrient context. On the basis of biomass allocation, $S$. vulgare was observed to increase root allocation in response to strangers compared with siblings. This indicates that kin recognition occurs among $S$. vulgare siblings, supporting the kin selection theory (Dudley and File 2007, 2008; Murphy and Dudley 2009). Related individuals will behave more altruistically based on signals of root secretions (Dudley and File 2007; Biedrzycki et al. 2010). In contrast, G. max did not demonstrate kin recognition based on biomass allocation. This reflects that it may be not universal among self-incompatible plants (Masclaux et al. 2010), but this needs further investigation. Another explanation is that increased root biomass might be not necessary for kin recognition (Dudley and File 2008), e.g., Impatiens pallid, a shade plant, increases aboveground allocation to acquire more light when growing with strangers (Murphy and Dudley 2009). In this study, we did not observe increased aboveground allocation for G. max.

According to $\mathrm{N}$ uptake data, we observed a completely different pattern as suggested by biomass allocation. Numerous studies have suggested that greater root allocation should enhance belowground competitive ability (Dudley and File 2007). In this study, when grown with strangers, $S$. vulgare did not enhance their $\mathrm{N}$ uptake (Figs. 3 and 4), although it increased root allocation (Fig. 2). A possible explanation for this foraging

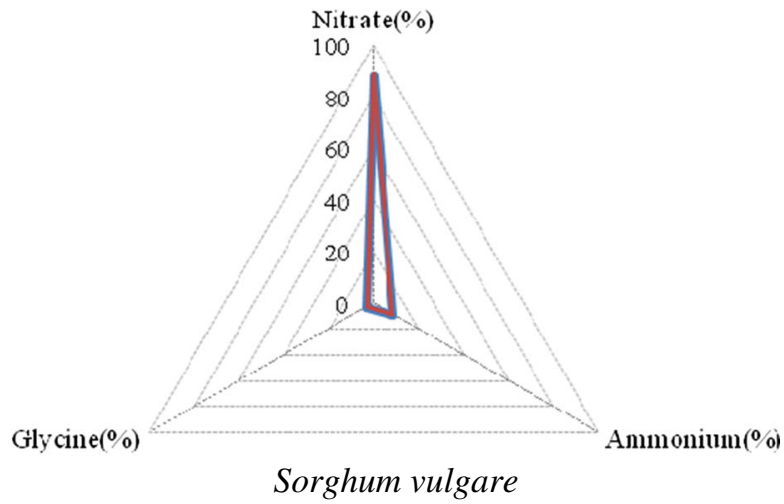

to total $\mathrm{N}$ uptake (as \%). Asterisks indicate significant difference $(P<0.05$ level) between sibling and strangers 
strategy (Chu et al. 2008; Cahill et al. 2010) is that plants increased root allocation through root elongation or larger overall surface area to occupy larger soil volumes (Morgan and Connolly 2013). For G. max, although increased root allocation was not observed when growing with strangers, they significantly increased total $\mathrm{N}$ uptake as well as the uptake of the dominant $\mathrm{N}$ (i.e., $\mathrm{NO}_{3}{ }^{-}$) and decreased the uptake of the less abundant $\mathrm{N}$ (i.e., glycine) (Figs. 3 and 4). When growing with siblings, G. max showed niche shift, increasing uptake of glycine but strongly decreasing uptake of $\mathrm{NO}_{3}{ }^{-}$. This kinship decreases total $\mathrm{N}$ uptake due to more niche overlap (Fig. 5), but also reflects resource partitioning between strangers and siblings (Cheplick and Kane 2004). We also suggest that kinship strongly decreases competition for dominant $\mathrm{N}$ through cooperation, while strangers strongly compete for the dominant $\mathrm{N}$ form (Figs. 3 and 4). However, two theories (i.e., kin selection and resource partitioning) cannot fully explain the cooperation and competition (Chu et al. 2008; Biernaskie 2011) between the siblings of these two crop species.

We found that G. max siblings did not exhibit kin recognition based on biomass allocation, but they significantly altered their competition for available N. Although $S$. vulgare invested more biomass to roots, this cost was not paid for enhancing the competition for available N. We suggest that this cost may be paid for space or water usage, but this requires further investigations. Masclaux et al. (2010) found biomass difference occurred when growing with different accessions, showing the interaction outcomes based on relative competitive ability. Andalo et al. (2001) suggested that intricate competitions may offset effects of kin selection between kin growing nearby. Here we conclude that interplay between facilitation and competition could lead to different competitive ability, providing better explanations for this (File et al. 2011).

In this study, plants grew in the field without any applied limitation to root growth (Fig. 1). Such design avoids the influence of pot size inequality and can separate complex roots clearly (Klemens 2008; Chen et al. 2012), but could decrease interactions between plants due to more space available for growth. Plants respond differently to kin neighbors and have contrasting results according to above- or belowground allocation and fitness (Cheplick and Kane 2004; Dudley and File 2007). The discrepancies may be attributed to different competitive traits which are expressed as kin selection or resource partitioning among different plant species. Nonetheless, this is the first report to show interactions between siblings for available $\mathrm{N}$ based on ${ }^{15} \mathrm{~N}$ tracers. This provides a new insight through the process of competing $\mathrm{N}$ as siblings growing, instead of using fitness, phenotype or allocation traits singly.

In conclusion, different interaction mechanisms (e.g., kin selection and resource partitioning) may occur simultaneously for siblings growing together (File et al. 2011), finally affecting plants competitive ability. Many previous experiments assumed that kin selection and resource partitioning occur independently, so that their discussions could be not comprehensive. Our findings reflect that interactions between siblings could be more complicated than previously expected. Although we only investigated two plant species, this aspect of kin selection may be a common phenomenon.

Acknowledgments We thank Douglas Schaefer and Sina Adl for language improvements. This study was supported by Natural Science Foundation of China (31470560).

\section{References}

Andalo C, Goldringer I, Godelle B (2001) Inter- and intragenotypic competition under elevated carbon dioxide in Arabidopsis thaliana. Ecology 82:157-164

Bever JD, Dickie IA, Facelli E, Facelli JM, Klironomos J, Moora M, Zobel M (2010) Rooting theories of plant community ecology in microbial interactions. Trends Ecol Evol 25(8): 468-478

Bhatt MV, Khandelwal A, Dudley SA (2011) Kin recognition, not competitive interactions, predicts root allocation in young Cakile edentula seedling pairs. New Phytol 189(4):1135-1142

Biedrzycki ML, Bais HP (2010) Kin recognition in plants: a mysterious behaviour unsolved. J Exp Bot 61:4123-4128

Biedrzycki ML, Jilany TA, Dudley SA, Bais HP (2010) Root exudates mediate kin recognition in plants. Commun Integr Biol 3(1):28-35

Biernaskie JM (2011) Evidence for competition and cooperation among climbing plants. Proc R Soc B Biol Sci 278: 1989-1996

Cahill JF, McNickle GG, Haag JJ, Lamb EG, Nyanumba SM, Clair CCS (2010) Plants integrate information about nutrients and neighbors. Science 328:1657-1657

Chen BJ, During HJ, Anten NP (2012) Detect thy neighbor: identity recognition at the root level in plants. Plant Sci 195:157-167

Cheplick GP (1992) Sibling competition in plants. J Ecol 80(3): 567-575

Cheplick GP, Kane KH (2004) Genetic relatedness and competition in Triplasis purpurea (Poaceae): resource partitioning or kin selection? Int J Plant Sci 165:623-630 
Chu CJ, Maestre FT, Xiao S, Weiner J, Wang YS, Duan ZH, Wang G (2008) Balance between facilitation and resource competition determines biomass-density relationships in plant populations. Ecol Lett 11:1189-1197

Dudley SA, File AL (2007) Kin recognition in an annual plant. Biol Lett 3:435-438

Dudley SA, File AL (2008) Yes, kin recognition in plants! Biol Lett 4:69-70

File AL, Murphy GP, Dudley SA (2011) Fitness consequences of plants growing with siblings: reconciling kin selection, niche partitioning and competitive ability. Proc R Soc B Biol Sci 279(1727):209-218

Gao JQ, Mo Y, Xu XL, Zhang XW, Yu FH (2014) Spatiotemporal variations affect uptake of inorganic and organic nitrogen by dominant plant species in an alpine wetland. Plant Soil 381: 271-278

Hamilton WD (1964) The genetical evolution of social behaviour. I. J Theor Biol 7:1-16

Kalembasa SJ, Jenkinson DSA (1973) Comparative study of titrimetric and gravimetric methods for determination of organic carbon in soil. J Sci Food Agric 24:1085-1090

Klemens JA (2008) Kin recognition in plants? Biol Lett 4(1):67-68

LeBauer DS, Treseder KK (2008) Nitrogen limitation of net primary productivity in terrestrial ecosystems is globally distributed. Ecology 89:371-379

Masclaux F, Hammond RL, Meunier J, Gouhier-Darimont C, Keller L, Reymond P (2010) Competitive ability not kinship affects growth of Arabidopsis thaliana accessions. New Phytol 185(1):322-331

McKane RB, Johnson LC, Shaver GR, Nadelhoffer KJ, Rastetter EB, Fry B, Giblin AE, Kielland K, Kwiatkowski BL, Laundre JA (2002) Resource-based niches provide a basis for plant species diversity and dominance in arctic tundra. Nature 415:68-71

Milla R, Forero DM, Escudero A, Iriondo JM (2009) Growing with siblings: a common ground for cooperation or for fiercer competition among plants? Proc R Soc B Biol Sci 276:2531-2540

Morgan JB, Connolly EL (2013) Plant-soil interactions: nutrient uptake. Nat Educ Knowl 4(8):2

Murphy GP, Dudley SA (2009) Kin recognition: competition and cooperation in Impatiens (Balsaminaceae). Am J Bot 96: 1990-1996

Näsholm T, Sandberg G, Ericsson A (1987) Quantitative-analysis of amino-acids in conifer tissues by high-performance liquidchromatography and fluorescence detection of their 9fluorenylmethyl chloroformate derivatives. J Chromatogr 396:225-236

Reynolds HL, Packer A, Bever JD, Clay K (2003) Grassroots ecology: plant-microbe-soil interactions as drivers of plant community structure and dynamics. Ecology 84(9): 2281-2291

Simonsen AK, Chow T, Stinchcombe JR (2014) Reduced plant competition among kin can be explained by Jensen's inequality. Ecol Evol 4(23):4454-4466

Vitousek PM, Howarth RW (1991) Nitrogen limitation on land and in the sea: how can it occur? Biogeochemistry 13:87-115

Xu XL, Ouyang H, Cao GM, Richter A, Wanek W, Kuzyakov Y (2011) Dominant plant species shift their nitrogen uptake patterns in response to nutrient enrichment caused by a fungal fairy in an alpine meadow. Plant Soil 341:495-504

Zhang JB, Cai ZC, Zhu TB, Yang WY, Müller C (2013) Mechanisms for the retention of inorganic $\mathrm{N}$ in acidic forest soils of southern China. Sci Rep 3: doi 10.1038/srep02342 